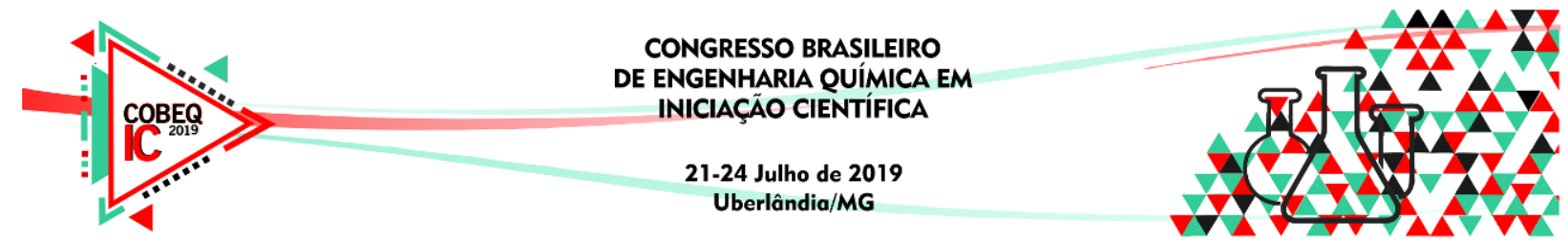

\title{
POLIÉSTER COM REFORÇO HÍBRIDO DE TECIDO DE FIBRAS DE JUTA E RESÍDUO DE MADEIRA: COMPORTAMENTO EM TRAÇÃO
}

\author{
G.F. MIRANDA ${ }^{1}$, L.R. ARAÚJO ${ }^{1}$, EDIELSON S. VILHENA ${ }^{1}$, EDIL S. VILHENA $^{1}$ e R.T. \\ FUJIYAMA $^{1}$ \\ ${ }^{1}$ Universidade Federal do Pará, Faculdade de Engenharia Mecânica \\ E-mail para contato: leonardoaraujo.ufpa@gmail.com
}

\begin{abstract}
RESUMO - Este trabalho foi desenvolvido com o intuito de se obter o desempenho mecânico de materiais híbridos em esforços de tração. Fora utilizado a matriz polimérica de resina poliéster, adicionalmente com o iniciador de cura Peróxido de MEK M-50, fibra natural de juta em disposição de tecido em $28 \mathrm{~cm} \mathrm{x}$ $32 \mathrm{~cm}$, juntamente com a adição de rejeitos da indústria madeireira que foram utilizados na forma de Muiracatiara e Tatajuba. Inicialmente, foi pensada uma metodologia de fabricação manual que se adeque à composição dos materiais híbridos para originar os corpos de prova segundo a norma ASTM D 3039. Foi montado o compósito sanduíche em forma de placa para posterior processo em prensa hidráulica e corte em serra mecânica, segundo as dimensões exigidas, para a retirada dos corpos de prova e a realização do posterior ensaio. $\mathrm{O}$ compósito feito com resíduo de tatajuba obteve resultados superiores ao de Muriacatiara, apresentando uma carga máxima média de 3.281,60 N e uma tensão média na carga máxima de $52,51 \mathrm{~N}$.
\end{abstract}

\section{INTRODUÇÃO}

Material compósito é a classificação de dois ou mais materiais que unidos originam uma nova composição, com características mecânicas não existentes nos componentes analisados isoladamente. Geralmente, um compósito é composto por duas fases heterogêneas, uma contínua chamada matriz e outra fase descontínua chamada reforço, produzindo materiais com características potencializadas (Callister, 2016).

Devido à possibilidade de obter diversas propriedades mecânicas em um único material, o campo de pesquisa de materiais compósitos tem sido alvo de investimentos maciços da indústria. Atualmente, as necessidades dessas indústrias têm sido supridas por uma designação desses materiais chamados Compósitos Avançados que se utilizam de fibras sintéticas, de origem fóssil. Ainda que com desempenhos fantásticos, possibilitando feitos que não seriam possíveis nas ultimas décadas com os materiais tradicionais, há dependência em relação à fonte de matéria-prima fóssil.

Pensando nisso, vem crescendo a preocupação em desenvolver materiais reforçados com elementos naturais de origem renovável, que possam alcançar no mínimo desempenho satisfatório perante aqueles sintéticos e num futuro embasado em intensas pesquisas, ter 


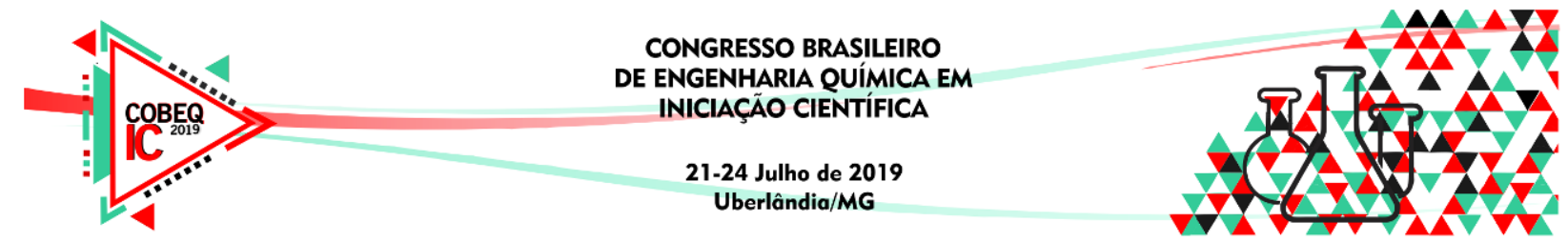

possibilidade de conter essa dependência. Uma das apostas, referente ao uso de fibras naturais, é a fibra lignocelulósica de juta (Corchorus capsularis) que vem sendo investigada em várias pesquisas. A fibra de juta possui baixo custo, abundância, maleabilidade e apresenta um bom conjunto de propriedades como, por exemplo, elevado módulo e resistência específica (Mello et al., 1995).

Com isto, aliando a realidade amazônica ao contexto de busca pelo desenvolvimento sustentável com a utilização de materiais compósitos e o desenvolvimento de materiais provenientes de fontes renováveis, este trabalho propõe o desenvolvimento de material compósito poliéster, reforçado por fibra natural de juta e resíduos de madeira da flora regional em forma de rejeito da indústria madeireira local.

Portanto, este trabalho de pesquisa tem como objetivo avaliar o comportamento em tração de materiais compósitos de matriz poliéster e reforço híbrido de tecido de juta e resíduo de madeira, segundo a norma ASTM D 3039.

\section{MATERIAIS E MÉTODOS}

\subsection{Materiais}

Fibras de Juta: A fibra de juta utilizada neste estudo foi em forma de tecido, obtido no comércio local aos arredores de Belém, conhecido como Ver-o-Peso, para fim de fabricação de cortes menores com dimensão de $28 \mathrm{~cm}$ x $32 \mathrm{~cm}$ que resultaram nas placas finais para o corte dos corpos de prova, como será explicado posteriormente.

Resíduo de madeira: Como reforço, foram utilizados dois tipos de resíduo de madeira, a muiracatiara e a tatajuba, adquiridas como rejeito da indústria madeireira local no mesmo estado no qual seriam descartadas no meio ambiente.

\subsection{Métodos}

Confecção dos Corpos de Prova: A manufatura dos compósitos efetuou-se através de um processo manual realizado em seis etapas principais, conforme a Figura 1, que consistiram na preparação do recheio de resina e resíduo; preparação das bases de madeiras nas quais foram montadas as placas híbridas com dimensões $12 \mathrm{~cm}$ x $28 \mathrm{~cm}$; produção das cascas; tempo de cura das placas; cortes dos corpos de prova e preparação dos mesmos para o ensaio.

Figura 1 - Esquema de produção.

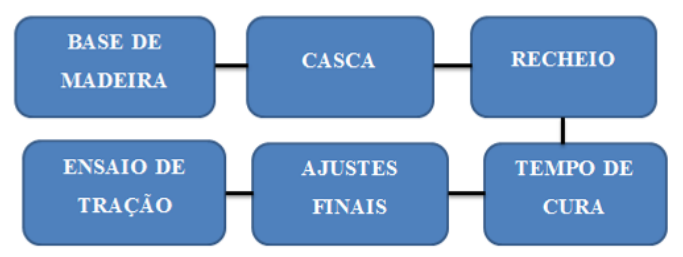

Inicialmente foram determinadas as quantidades de resina e catalisador para a preparação das cascas (tecido de fibra de juta revestido com resina poliéster curada sobre o efeito de catalisador) e para a produção do recheio (resíduo de madeira misturado à resina 


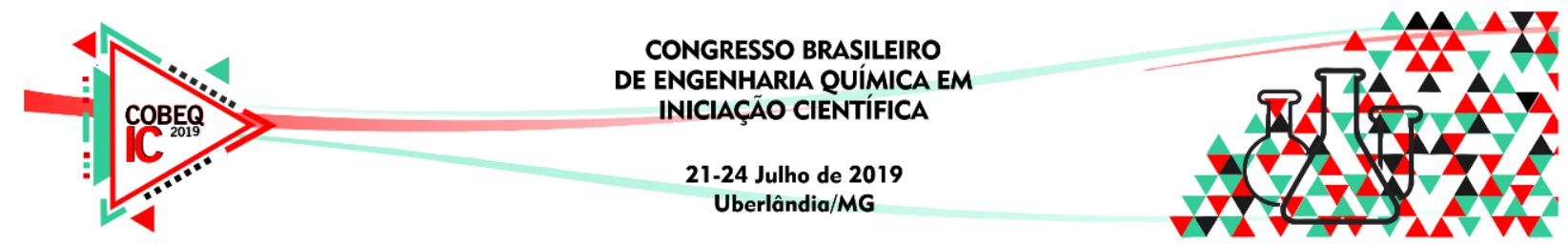

poliéster em processo de cura sob efeito de catalisador). Este processo baseou-se em trabalhos anteriores que utilizaram uma relação de volume em massa de resina com $0,33 \%$ de catalisador, como o de Rodrigues (2008). A Tabela 1 mostra as quantidades de resinas utilizadas.

Tabela 1 - Quantidades de resina utilizadas

\begin{tabular}{|c|c|c|}
\hline $\begin{array}{c}\text { Parâmetro das quantidades } \\
\text { resina/catalisador }\end{array}$ & Volume (ml) & Massa (g) \\
\hline \hline Resina casca & 210,00 & 258,00 \\
\hline Iniciador casca & 0,69 & 0,57 \\
\hline Resina recheio & 166,45 & 204,50 \\
\hline Iniciador recheio & 1,18 & 1,07 \\
\hline
\end{tabular}

A primeira etapa consistiu em preparar as bases de madeira retangulares, $36 \mathrm{~cm} \mathrm{x} 41$ $\mathrm{cm}$, que serviram para a montagem das placas e para o posterior processo de cura em prensa hidráulica. Estas placas foram forradas com folhas finas de plástico transparente preso por fita adesiva ao suporte, com o intuito de impedir que o material compósito tivesse contato direto com a madeira, evitando absorção de qualquer componente da mistura por ela. Além de revertidas com plástico, elas foram dimensionadas para que comportasse em seu ponto central o tecido de juta.

Basicamente a preparação das bases consistiu dos seguintes processos. $1^{\circ}$ processo: vedá-las com plástico transparente com o auxílio de fita adesiva; $2^{\circ}$ processo: dimensioná-las de acordo com as dimensões do tecido, certificando-se que o tecido fique centralizado sobre o suporte; $3^{\circ}$ processo: verificar se o processo culminou nas dimensões do tecido e se o tecido ficou centralizado sobre o suporte.

A segunda etapa consistiu na preparação das cascas do compósito sanduíche. Sobre os dois suportes de madeira necessários para a produção de uma placa foi despejada certa quantidade de resina das $258 \mathrm{~g}$ já determinada, de modo a revestir de resina um lado do tecido de juta sobre seu respectivo suporte. Em seguida, foi disposto o tecido e mais resina, até que toda a quantidade fosse utilizada de maneira igual e uniforme nas duas cascas. Conforme Figura 2.

Figura 2 - Confecção das Placas de Madeira.

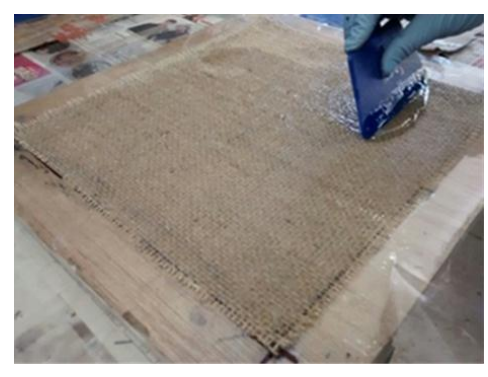

Este processo obedece à sequência resina/juta/resina. De modo que as quantidades de resina em cada camada sejam de acordo com o necessário para envolver os tecidos nos dois lados, inferior e superior. O processo finalizou-se com o tempo de cura das cascas até o dia seguinte. 


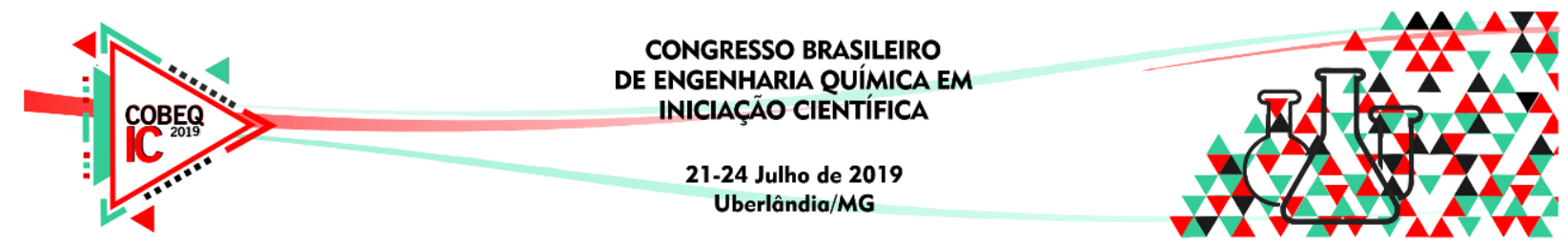

A cura prévia das cascas do compósito evitou que a placa sanduiche expulsasse resina quando sobre pressão na prensa hidráulica e facilitou o espalhamento do recheio sobre elas.

A terceira etapa, produção do recheio, seguiu-se com a pesagem da quantidade de resíduo de madeira utilizado para 204,5 g de resina com 1,07 g de catalisador. A quantidade de resíduo utilizado foi conforme a resina poderia suportar, em vista da maior fração mássica possível.

Antes de se efetuar a mistura do resíduo de madeira com a resina, foi realizado o seu aquecimento em forno micro-ondas, com o objetivo de eliminar resquícios de umidade que poderiam prejudicar o processo de cura da placa ou interferir negativamente em qualquer outro desempenho final do processo. Seguiu-se à produção do recheio, com a mistura de resíduo à resina poliéster.

Terminada esta etapa, fora realizado a unificação do conjunto recheio e cascas para a formação da lâmina de compósito híbrido. Para isto, a mistura do recheio foi despejada sobre as duas cascas, uma a uma, até que elas apresentassem um aspecto uniforme e igual de material recebido sobre si. Este processo foi denominado espalhamento duplo, uma vez que a distribuição do material sobre as duas cascas evitou mais a presença de "vazios" no interior da placa do que quando se despejava em uma única banda, antes de uni-las uma sobre a outra.

Por fim, foi necessário fazer uso de pregos para delimitar o centro e as bordas da placa. Esse processo foi feito somente sobre uma das cascas. Os pregos que compõem o centro da casca foram cerrados para que sua superfície de contato maior não impedisse a disposição de uma placa sobre a outra, conforme Figura 3. A utilização desse método se fez necessário para que o processo de prensa não comprimisse o recheio a ponto de expulsá-lo do conjunto.

Figura 3 - Pregos sobre o recheio.

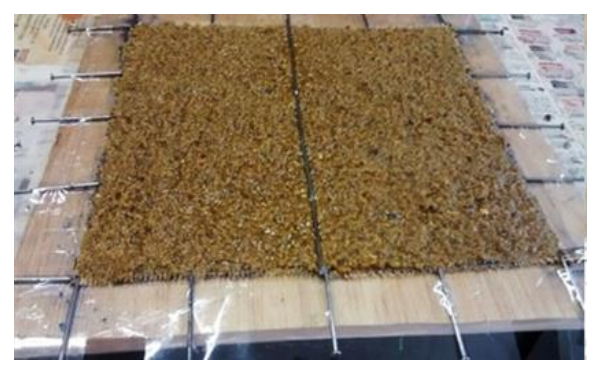

Seguiu-se a disposição de uma casca sobre a outra, finalizando o processo de laminação. Em seguida foi posta sobre pressão de 2 ton em prensa hidráulica, até o processo de cura que perdurou de quatro a cinco horas, aproximadamente. O desmolde da placa, porém, das bases de madeira foram realizadas apenas no dia seguinte, com a finalização de todo processo de fabricação.

Acabamento dos corpos de prova: Foi esperada uma semana após a produção da placa para que se iniciasse o processo de corte dos corpos de prova segundo a norma estabelecida, a ASTM D 3039, conforme Figura 4. Isso foi muito importante, visto que processos como corte e lixamento elevam o nível da temperatura sobre a superfície de contato dos corpos de prova e 


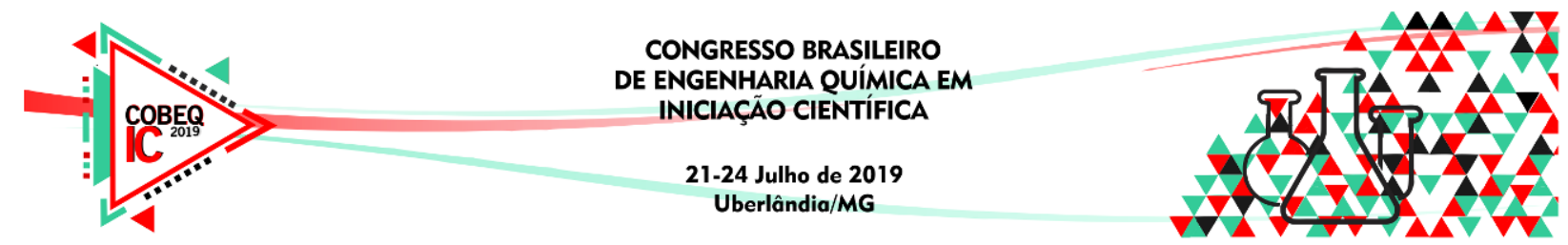

prejudicam a estrutura dos mesmos se a resina estiver mal curada. Em outras palavras, o corpo de prova fica mole e flexível.

Figura 4 - Corpos de Prova.

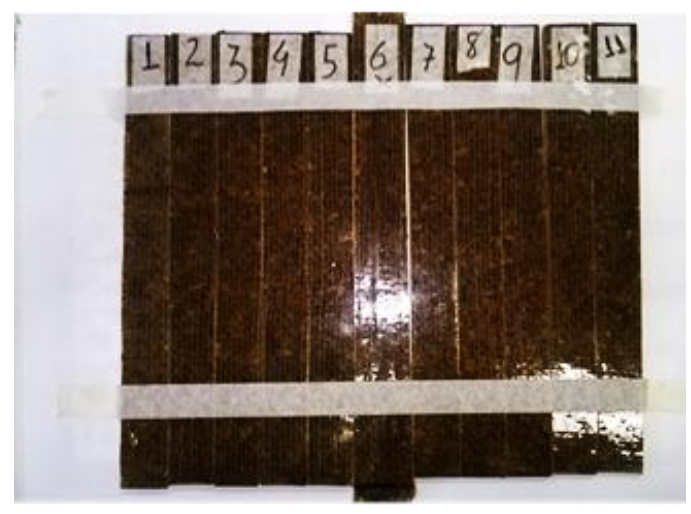

Considerando o comprimento útil, em concordância com a norma já referenciada, foram demarcadas três partes sobre o corpo de prova para que se limitasse o local onde seria colado o Tab. Finalizado isto, passado tempo suficiente para secagem da cola, foi utilizada lixa 120 mm como Tab. Assim, os corpos de prova estavam prontos para o ensaio em tração.

\section{RESULTADOS E DISCUSSÕES}

As propriedades mecânicas médias obtidas a partir dos ensaios de tração são apresentadas na Tabela 2.

Tabela 2 - Propriedades mecânicas em tração dos compósitos

\begin{tabular}{|c|c|c|c|c|c|}
\hline Tipo de Compósito & $\begin{array}{c}\text { Fração } \\
\text { mássica (\%) }\end{array}$ & $\begin{array}{c}\text { Carga } \\
\text { Máxima (N) }\end{array}$ & $\begin{array}{c}\text { Tensão na } \\
\text { Carga } \\
\text { Máxima } \\
(\mathrm{MPa})\end{array}$ & $\begin{array}{c}\text { Deformação na } \\
\text { Carga Máxima } \\
(\mathrm{mm})\end{array}$ & $\begin{array}{c}\text { Módulo } \\
\text { Elástico } \\
(\mathrm{MPa})\end{array}$ \\
\hline Juta/Muiracatiara/Juta & 23,70 & $\begin{array}{c}2258,02 \\
( \pm 409,13)\end{array}$ & $36,13( \pm 6,55)$ & $5,45( \pm 0,66)$ & $\begin{array}{c}915,86 \\
( \pm 154,39)\end{array}$ \\
\hline Juta/Tatajuba/Juta & 21,75 & $\begin{array}{c}3281,60 \\
( \pm 435,14)\end{array}$ & $52,51( \pm 6,96)$ & $6,25( \pm 0,02)$ & $\begin{array}{c}1254,69 \\
( \pm 131,23)\end{array}$ \\
\hline
\end{tabular}

Após a análise dos resultados, levando-se em conta a fração mássica de ambos, que apesar de não podermos tirar uma conclusão sem fazer testes para analisar especificamente sua relevância, que pode influenciar de forma direta nas 4 propriedades analisadas, verifica-se que os compósitos compostos por resíduo de tatajuba e resíduo de muiracatiara apresentaram bons desempenhos mecânicos, em especial o de tatajuba, que apresentou um bom valor no limite de resistência à tração e também no módulo elástico, $52,51 \mathrm{MPa}$ e $1254,69 \mathrm{MPa}$, respectivamente, enquanto que o compósito de resíduo de muiracatiara apresentou 36,13 MPa e 915,86 MPa para as mesmas propriedades. 


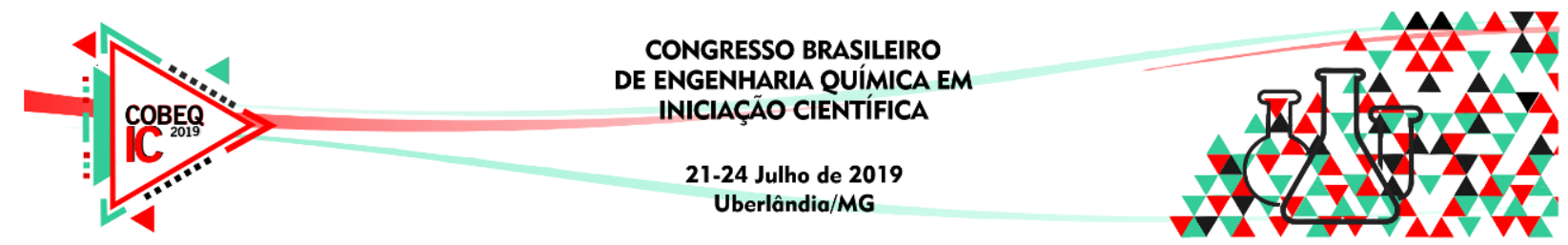

Quanto à carga máxima suportada, o compósito de tatajuba também apresentou um valor mais relevante, com uma diferença de 1.023,58 N. Com o desvio apresentado pela deformação na carga máxima dos dois compósitos, pode-se ver que o de muiracatiara possuiu valores bem diferentes para os resultados, enquanto que o de tatajuba apresentou valores mais constantes, variando pouco em torno da média de $6,25 \mathrm{~mm}$, um fator importante a ser considerado para compreendermos bem os limites de um material.

\section{CONCLUSÃO}

De modo geral, os compósitos compostos por resíduo de muiracatiara e resíduo de tatajuba apresentaram bons desempenhos mecânicos, como desejados, nos ensaios realizados. Podemos concluir que o compósito com resíduo de tatajuba apresentou propriedades mecânicas superiores ao compósito com resíduo de muiracatiara, com destaque para a resistência à tração e a força, ambas $45,3 \%$ superior ao compararmos o material reforçado pela tatajuba com o reforçado pela muiracatiara, já o módulo de elasticidade apresenta-se $37 \%$ superior fazendo a mesma comparação. Isso pode ser devido, também, à fração mássica desses resíduos, pois apesar de o resíduo de muiracatiara apresentar uma fração mássica maior em comparação à fração mássica de resíduo de tatajuba, isso pode ter levado a uma fragilização do material.

Esses resultados mostram que sua utilização é viável para a fabricação de compósitos e que pode representar uma nova forma de reutilização de materiais que seriam despejados pela indústria, um grande benefício para a realidade atual da Amazônia e a busca do desenvolvimento sustentável com a utilização de fontes renováveis.

\section{REFERÊNCIAS}

ALVES, R.T. Embrapa Cerrados celebra centenário da imigração japonesa.

Cerrados Informa. Planaltina, v. 9, n. 88, p. 2, 2008.

CALLISTER, W. D. Fundamentos da ciência e engenharia de materiais. 2.ed. Rio de Janeiro: LTC, 2006.

MELLO, M.L.S.; CONTENTE, S.; VIDAL, B.C.; PLANDING, W.; SCHENCK, U. Modulation of ras transformation affecting chromatin supraorganization as assessed by image analysis. Exp. Cell Res, v. 220, p. 374-382, 1995.

RODRIGUES, J. da S. Comportamento mecânico de material compósito de matriz poliéster reforçado por sistema híbrido fibras naturais e resíduos da indústria Madeireira. Belém: 2008, 91 f. Dissertação (Mestrado em Engenharia: Materiais e processos de Fabricação) - Faculdade de Engenharia Mecânica, Instituto de Tecnologia, Universidade Federal do Pará, Belém, 2008.

RODRIGUEZ, F. Principies of Polymer Systems. Taylor \& Francis. Washington, DC, 1996. 